\title{
An efficient method for the sanitary vitrification of bovine oocytes in straws
}

\author{
Yanhua Zhou', Xiangwei Fu', Guangbin Zhou ${ }^{3}$, Baoyu Jia ${ }^{1}$, Yi Fang ${ }^{1}$, Yunpeng Hou ${ }^{2}$ and Shien Zhu*
}

\begin{abstract}
Background: At present, vitrification has been widely applied to humans, mice and farm animals. To improve the efficiency of vitrification in straw, bovine oocytes were used to test a new two-step vitrification method in this study.

Results: When in vitro matured oocytes were exposed to 20\% ethylene glycol (EG20) for 5 min and 40\% ethylene glycol (EG40) for $30 \mathrm{~s}$, followed by treatment with $30 \%$ glycerol (Gly30), Gly40 or Gly50, a volume expansion was observed in Gly30 and Gly40 but not Gly50. This indicates that the intracellular osmotic pressure after a 30 s differs between EG40 and ranged between Gly40 (approximately $5.6 \mathrm{~mol} / \mathrm{L}$ ) and Gly50 (approximately $7.0 \mathrm{~mol} / \mathrm{L}$ ). Since oocytes are in EG40 just for only a short period of time $(30 \mathrm{~s})$ and at a lower temperature $\left(4^{\circ} \mathrm{C}\right)$, we hypothesize that the main function of this step in to induce dehydration. Based on these results, we omitted the EG40 step, before oocytes were pretreated in EG20 for 5 min, exposed to pre-cooled $\left(4^{\circ} \mathrm{C}\right) \mathrm{Gly} 50$, for $30 \mathrm{~s}$, and then dipped into liquid nitrogen. After warming, $81.1 \%$ of the oocytes survived, and the surviving oocytes developed into cleavage stage embryos (63.5\%) or blastocysts (20.0\%) after parthenogenetic activation.
\end{abstract}

Conclusions: These results demonstrate that in a two-step vitrification procedure, the permeability effect in the second step is not necessary. It is possible that the second step is only required to provide adequate osmotic pressure to condense the intracellular concentration of CPAs to a level required for successful vitrification.

Keywords: Bovine, Cryopreservation, Oocytes, Straw, Vitrification

\section{Background}

Vitrification is the rapid cooling of cells in liquid medium in the absence of ice crystal formation. Vitrification can be achieved when the intracellular concentration of cryoprotective agents (CPAs) is higher than $6 \mathrm{~mol} / \mathrm{L}$ [1]. The benefits of a two-step vitrification method are that it allows establishment of a relatively complete equilibrium while reducing exposure of the oocyte to potential toxic effects of CPAs. Previously, oocytes or embryos were first exposed to non-vitrifying solutions containing permeating CPAs $[2,3]$. Next, the oocytes were exposed for a short time (45-60 s) to a vitrifying solution (VS) containing high concentrations of penetrating $(4.8-6.4 \mathrm{~mol} / \mathrm{L})$ and non-penetrating $(0.5-$

\footnotetext{
* Correspondence: zhushien@cau.edu.cn

${ }^{1}$ National Engineering Laboratory for Animal Breeding, Key Laboratory of Animal genetics, Breeding and Reproduction, Ministry of Agriculture, College of Animal Science and Technology, China Agricultural University, Beijing 100193, P.R. China

Full list of author information is available at the end of the article
}

$0.75 \mathrm{~mol} / \mathrm{L}$ ) CPAs before being plunged into liquid nitrogen (LN2) [2-4].

Since the first successful vitrification of mouse embryos by Rall and Fahy in 1985 [1], this method has been used widely for oocyte and embryo cryopreservation. Numerous research articles have focused on CPA permeability and the rate at which it enters cells $[5,6]$. Other studies have investigated incubation times in both the pretreatment and vitrification solutions and found that the temperature used during the handling procedure is also important for successful vitrification [7-9]. The open-pulled straw (OPS) method originally described by Vajta and colleagues, allows for faster heat transfer between the solution and the environment, achieving cooling/warming rates on the order of $20,000^{\circ} \mathrm{C} / \mathrm{min}$ [10]. In 1999, when Le Gal and Massip compared three approaches (standard 0.25-mL straw, OPS, and Microdrop) for cooling a vitrification solution containing bovine oocytes, the highest cleavage rate was achieved with the traditional straw [11]. Dinnyés and colleagues [12] 
described the use of solid-surface vitrification (SSV). In 2004, an early report using cryotops for bovine oocyte vitrification was published [13]. These variations make the vitrification method seem difficult to master which has limited the application of this technology in the field of reproductive biology.

Cells react to changes in extracellular osmolarity by altering their volume. Cells exposed to hypotonic or hypertonic solutions initially react either by swelling (hypotonic solutions) or shrinking (hypertonic solutions) due to water exchange but later recover as permeant solutes equilibrate across the cell membrane $[4,5,14,15]$. Vanderzwalmen et al. $[3,4]$ estimated the final intracellular concentration of cryoprotectant (ICCP) after incubation in vitrification solutions by exposing cells to sucrose solutions with defined molarities. The ICCP was calculated from the sucrose concentration that produced no change in cell volume, i.e., when intra- and extracellular osmolarities were equivalent [4].

In 1977, Whittingham successfully cryopreserved mouse oocytes [16]. Bovine oocytes were also vitrified and remained viable for offspring production after in vitro fertilization and embryo transplantation [17,18]. vitrified buffalo oocytes with $51.1 \%$ glycerol via the straw method, obtaining a maturation rate of $23.5 \%$ after thawing [18]. When glycerol was used with EG, which increased permeability of the cell membrane during oocyte vitrification, and maturation rates of $30 \mathrm{~s}$ exposure groups did not differ from those of controls [19]. Additionally, the OPS (open pulled straw) method results in a better survival rate during cryopreservation than the straw method [20]. However, unlike other methods, the straw method is safer for oocyte vitrification because the oocytes are free of bacterial contamination due to a lack of direct contact with liquid nitrogen.

In our experiments glycerol was used as an extracellular measure for ICCP. In the first part of this study, bovine oocytes were used to test changes in intracellular cryoprotectant concentration during a widely used twostep vitrification method. Oocytes were pretreated with 20\% EG (EG20) for $5 \mathrm{~min}$, transferred to pre-cooled $\left(4^{\circ} \mathrm{C}\right) 40 \%$ EG (EG40) for $30 \mathrm{~s}$, then treated with precooled glycerol either at 30\% (Gly30), 40\% (Gly40) or $50 \%$ (Gly50) concentration. The intracellular EG molarity was then determined from the extracellular glycerol molarity. In the second part of the experiment, oocytes were pretreated with EG20 for $5 \mathrm{~min}$, transferred directly to pre-cooled $\left(4^{\circ} \mathrm{C}\right) 50 \%$ glycerol (Gly50) for $30 \mathrm{~s}$, and then plunged directly into liquid nitrogen for cryopreservation in an insemination straw. Vitrified-warmed oocytes were parthenogenetically activated and cultured in vitro to assess viability.

In this study, experiments were designed to improve the efficacy of vitrification in straws. To optimize the ideal CPA treatment for this two-step vitrification method, different cryoprotectants (EG and Gly) were used in each step, which differs from methods reported previously. It has been reported that the permeability of glycerol is relatively low [14]. The present experiments examined whether CPA permeability during the second step is a key factor for vitrification. We investigated the possibility that the second equilibration step provides a high osmotic pressure increase intracellular CPA to a level required for successful vitrification.

\section{Methods}

The Institution Animal Care and Use Committee at China Agricultural University (Beijing, China) reviewed and approved the protocols used in this study. All chemicals and media were purchased from Sigma Chemical Co. (St. Louis, MO, USA) unless otherwise indicated.

\section{Solution preparation}

Modified phosphate-buffered saline (mPBS) was prepared by adding $10 \%(\mathrm{v} / \mathrm{v})$ fetal bovine serum (FBS, Gibco), $0.3 \%(\mathrm{w} / \mathrm{v}) \mathrm{BSA}$ and $50 \mathrm{mg} / \mathrm{mL}$ gentamycin to Dulbecco's phosphate-buffered saline (DPBS, Gibco).

EG20 was prepared by adding $20 \%$ (v/v) ethylene glycol to mPBS;

EG40 was prepared by adding $40 \%(\mathrm{v} / \mathrm{v})$ ethylene glycol to mPBS;

Gly30 was prepared by adding 30\% (v/v) glycerol to mPBS;

Gly40 was prepared by adding 40\% (v/v) glycerol to mPBS;

Gly50 was prepared by adding 50\% (v/v) glycerol to mPBS;

Dilution medium was $0.5 \mathrm{~mol} / \mathrm{L}$ sucrose in $\mathrm{mPBS}$.

\section{Oocyte collection and in vitro maturation}

Bovine (Bos taurus, 3 to $6 \mathrm{yr}$ of age) ovaries were transported from the abattoir to the laboratory in a physiological saline solution at $26^{\circ} \mathrm{C}$ to $30^{\circ} \mathrm{C}$ within $2 \mathrm{~h}$ of slaughter. Antral follicles (2 $\mathrm{mm}$ to $8 \mathrm{~mm}$ in diameter) were manually aspirated using an 18-gauge needle attached to a $10 \mathrm{~mL}$ syringe. Oocytes with at least four layers of compact cumulus cells (COCs) were selected for in vitro maturation (IVM). Oocytes were washed three times in HEPES-buffered TCM-199 medium and then washed twice in $\mathrm{NaHCO}_{3}$-buffered TCM-199. Fifty COCs were transferred to $0.75 \mathrm{~mL}$ maturation medium (M199 with $10 \mathrm{mg} / \mathrm{mL}$ oFSH [Ovagen, Auckland, New Zealand], $10 \mathrm{mg} / \mathrm{mL}$ oLH [Ovagen], $1 \mathrm{mg} / \mathrm{mL}$ estradiol [Ovagen] and $10 \%$ fetal bovine serum [FBS; Gibco]) in 4-well plates (Nunclon). The COCs were cultured for $22 \mathrm{~h}$ at $38.5^{\circ} \mathrm{C}$ in a humidified atmosphere with $5 \% \mathrm{CO}_{2}$. Oocytes were denuded after $22 \mathrm{~h}$ maturation by repeated pipetting with a $200 \mu \mathrm{L}$ pipette for approximately $1 \mathrm{~min}$ in $38^{\circ} \mathrm{C} 0.1 \% \mathrm{w} / \mathrm{v}$. hyaluronidase. Cumulus-free oocytes 
with the first polar body were selected and randomly allocated to experimental groups.

\section{Oocyte volume}

Oocyte volumes were determined using established methods [14] with modifications. Oocytes were fixed in a $5 \mu \mathrm{L} \mathrm{mPBS}$ drop using a holding needle (outer diameter $50 \mu \mathrm{m}$; inner diameter $30 \mu \mathrm{m}$ ) attached to an Olympus inverted microscope, $200 \mu \mathrm{L}$ of EG20 was then flushed onto the drop. The drop of EG20 $(\sim 200 \mu \mathrm{L})$ was aspirated 5 min later with a transferpettor. In the second step, $500 \mu \mathrm{L}$ of pre-cooled $\left(4^{\circ} \mathrm{C}\right)$ EG40 (experiment 1-a) or Gly50 (experiment 1-e) was flushed into the drop. For Experiments 1-b, c and d, $200 \mu \mathrm{L}$ pre-cooled solution (EG40) was flushed into the drop. EG40 was aspirated off the oocyte after $30 \mathrm{~s}$, and then $500 \mu \mathrm{L}$ of pre-cooled $\left(4^{\circ} \mathrm{C}\right)$ glycerol solution (either of Gly30, Gly40 or Gly50) was flushed into the drop.

The entire procedure was video recorded using a CCD camera on an inverted microscope. Screenshots of the video recording were taken at the desired times. Crosssectional areas of the oocytes were calculated using EZC1 3.00 Free Viewer software. The relative change in volume was determined according to a previously pubulished method [10]. Briefly, the oocyte area relative to that in isotonic mPBS medium was calculated and converted into a relative volume (considered as $1 \mathrm{~V}$ ). The volume was assumed to change proportionally, and the equation $\mathrm{V}=\mathrm{S}^{3 / 2}$ was used, where $\mathrm{S}$ is relative crosssectional area and $\mathrm{V}$ is the relative volume. For each treatment, 5 oocytes were examined.

\section{Oocyte vitrification and warming}

Oocytes were vitrified by a two-step method as previously reported, with modifications $[9,21,22]$. Briefly, oocytes were placed in EG20 for $5 \mathrm{~min}$ at $25^{\circ} \mathrm{C}$. The oocytes were then transferred to pre-cooled Gly50 for $30 \mathrm{~s}$, pipetted into sections of an insemination straw (250 $\mu \mathrm{L}$, IMV, L'Aigle, France), as shown in Figure 1. and then straws were sealed with seal powder and plunged into liquid nitrogen. Two oocytes were loaded into each straw.

After one week of storage in liquid nitrogen, the straws were plunged into $25^{\circ} \mathrm{C}$ water for $10 \mathrm{~s}$. As the crystallized sucrose solutions in the straw melted, the straws were removed from the water and quickly wiped dry. The straws were then held at the sealed end and shaken three times by hand to mix the vitrification solution and the sucrose solution. Subsequently, the seals of the straw were removed and the oocytes were expelled from the straw into a dry culture dish. Oocytes were put into fresh $0.5 \mathrm{~mol} / \mathrm{L}$ sucrose for $5 \mathrm{~min}$ and then washed in two other mPBS dishes for 5 min each.

After a 30 min recovery in $\mathrm{mPBS}$, the oocytes were assessed for survival. Surviving oocytes were those with regular, spherical shapes that were not lysed, shrunken, swollen or blackened. The surviving oocytes were parthenogenetically activated and cultured in vitro.

\section{Parthenogenetic activation}

Oocytes were washed three times in HEPES-buffered TCM-199 with 10\% FBS (H199) and then activated as follows: (1) incubation for $5 \mathrm{~min}$ in 7\% ethanol in IVM medium at room temperature and (2) cultured for $4 \mathrm{~h}$ in $2 \mathrm{mmol} / \mathrm{L}$ 6-DMAP in culture medium. Fifteen oocytes were transferred to $60 \mu \mathrm{L}$ Charles Rosenkran's 1 medium [23] with BSA (3 mg/mL, Sigma A3311) covered with mineral oil (Sigma M8410) in a $35 \mathrm{~mm} \times 35 \mathrm{~mm}$ Nunclon dish and cultured in an incubator $\left(38.5^{\circ} \mathrm{C}\right.$ with $5 \%$ $\mathrm{CO}_{2}$ in air) for up to $48 \mathrm{~h}$ before determining the rates of activation and cleavage. Cleaved embryos were cultured for an additional $5 \mathrm{~d}$ in Charles Rosenkran's 1 medium with $5 \%$ FBS.

\section{Experimental design}

Experiment 1. In this section oocytes were randomly allocated to five experimental groups, and each experiment was repeated five times.

(a) Oocytes were incubated in EG20 for 5 min followed by addition of pre-cooled $\left(4^{\circ} \mathrm{C}\right)$ EG40. Oocytes $\rightarrow$ EG20 $\left(25^{\circ} \mathrm{C}, 5 \mathrm{~min}\right) \rightarrow \mathrm{EG} 40$ ( $\left.4^{\circ} \mathrm{C}, 4 \mathrm{~min}\right)$.

(b) Oocytes were incubated in EG20 for 5 min, pre-cooled $\left(4^{\circ} \mathrm{C}\right) \mathrm{EG} 40$ for $30 \mathrm{~s}$, and then incubated in pre-cooled $\left(4^{\circ} \mathrm{C}\right)$ Gly30 for $3 \mathrm{~min}$. Oocytes $\rightarrow \mathrm{EG} 20\left(25^{\circ} \mathrm{C}\right.$, $5 \mathrm{~min}) \rightarrow$ EG40 $\left(4^{\circ} \mathrm{C}, 30 \mathrm{~s}\right) \rightarrow$ Gly30 ( $\left.4^{\circ} \mathrm{C}, 3 \mathrm{~min}\right)$.

(c) Oocytes were incubated in EG20 for 5 min, pre-cooled $\left(4^{\circ} \mathrm{C}\right)$ EG40 for $30 \mathrm{~s}$, and then pre-cooled $\left(4^{\circ} \mathrm{C}\right) \mathrm{Gly} 40$ for $3 \mathrm{~min}$. Oocytes $\rightarrow \mathrm{EG} 20\left(25^{\circ} \mathrm{C}, 5 \mathrm{~min}\right) \rightarrow$ EG40 $\left(4^{\circ} \mathrm{C}, 30 \mathrm{~s}\right) \rightarrow$ Gly 40 ( $\left.4^{\circ} \mathrm{C}, 3 \mathrm{~min}\right)$.

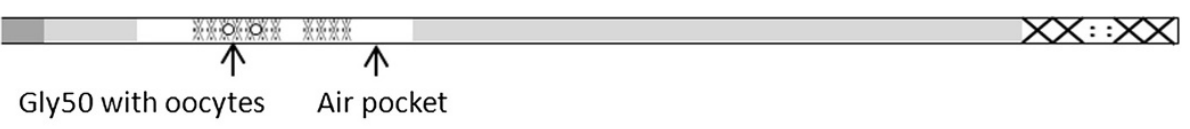

Cotton Plug: $\not X: X \quad 0.5 \mathrm{M}$ sucrose :

Gly50 : ※※※※※ Seal powder:

Figure 1 Cubing protocol: the sucrose solution in the plug end occupies $5.0 \mathrm{~cm}$, the section in which the oocytes are placed occupies $1.2 \mathrm{~cm}$ and a small volume of Gly50 lies to the right of the oocytes. 
(d) Oocytes were incubated in EG20 for 5 min, pre-cooled $\left(4^{\circ} \mathrm{C}\right) \mathrm{EG} 40$ for $30 \mathrm{~s}$, and then pre-cooled $\left(4^{\circ} \mathrm{C}\right) \mathrm{Gly} 50$ for $3 \mathrm{~min}$. Oocytes $\rightarrow \mathrm{EG} 20\left(25^{\circ} \mathrm{C}, 5 \mathrm{~min}\right) \rightarrow \mathrm{EG} 40$ $\left(4^{\circ} \mathrm{C}, 30 \mathrm{~s}\right) \rightarrow$ Gly50 ( $\left.4^{\circ} \mathrm{C}, 3 \mathrm{~min}\right)$.

(e) Oocytes were incubated in EG20 for 5 min and then pre-cooled $\left(4^{\circ} \mathrm{C}\right)$ Gly50 for $4 \mathrm{~min}$. Oocytes $\rightarrow$ EG20 $\left(25^{\circ} \mathrm{C}, 5 \mathrm{~min}\right) \rightarrow \operatorname{Gly} 50\left(4^{\circ} \mathrm{C}, 4 \mathrm{~min}\right)$.

The volume changes of oocytes during all of these procedures were analyzed and used to generate a curve diagram over time.

Experiment 2. Development of cryopreserved oocytes after parthenogenetic activation.

Cumulus-free oocytes with the first polar body and normal morphology were selected and allocated randomly to the following experimental groups:

(1) Control group: Oocytes without CPA treatment or vitrification were cultured after parthenogenetic activation.

(2) Toxicity group: Oocytes were exposed to the same solutions as the vitrification group but were not plunged into liquid nitrogen. These oocytes were diluted and parthenogenetically activated according to the procedure used for the vitrification group.

(3) Vitrification group: based on the results of experiment 1, oocytes were pre-treated in EG20 $\left(25^{\circ} \mathrm{C}\right)$ for $5 \mathrm{~min}$ and then transferred to Gly50 $\left(4^{\circ} \mathrm{C}\right)$ for $30 \mathrm{~s}$ before being plunged into liquid nitrogen.

\section{Statistical analysis}

Embryos development experiments were repeated three times. The percentage data were subjected to arcsine transformation before statistical analysis. The data were analyzed by one-way ANOVA combined with the LSD test. $P<0.05$ was considered statistically significant.

\section{Results}

Experiment 1.Oocytes volume changes for five different protocols:

(a) Oocytes $\rightarrow$ EG20 $\left(25^{\circ} \mathrm{C}, 5 \mathrm{~min}\right) \rightarrow \mathrm{EG} 40\left(4^{\circ} \mathrm{C}\right.$, $4 \mathrm{~min})$. When exposed to EG20, the oocytes shrank to $0.48 \mathrm{~V}(\diamond$ in Figure $2 \mathrm{a})$ in $20 \mathrm{~s}$ and then swelled slowly to $0.80 \mathrm{~V}$ after $5 \mathrm{~min}$ of exposure. When the oocytes were flushed with pre-cooled EG40, they shrank to $0.52 \mathrm{~V}(\Delta$ in Figure 2$)$ and then gradually swelled again.

(b) Oocytes $\rightarrow$ EG20 $\left(25^{\circ} \mathrm{C}\right.$, $\left.5 \mathrm{~min}\right) \rightarrow$ EG40 $\left(4^{\circ} \mathrm{C}, 30 \mathrm{~s}\right) \rightarrow \mathrm{Gly} 30\left(4^{\circ} \mathrm{C}, 3 \mathrm{~min}\right)$. At the end of the $30 \mathrm{~s}$ exposure to EG40, the oocytes shrank to $0.59 \mathrm{~V}(\diamond$ in Figure 2b). Subsequently, pre-cooled Gly30 was flushed over the oocytes and an expansion in volume to $0.65 \mathrm{~V}$ was observed (from $\diamond$ to $\Delta$, as shown in Figure 2b), indicating a higher intracellular osmotic pressure as compared to the extracellular pressure. After a 25-s exposure to Gly30, the oocytes began to gradually shrink in volume.

(c) Oocytes $\rightarrow$ EG20 $\left(25^{\circ} \mathrm{C}, 5 \mathrm{~min}\right) \rightarrow$ EG40 $\left(4^{\circ} \mathrm{C}, 30 \mathrm{~s}\right) \rightarrow$ Gly40 $\left(4^{\circ} \mathrm{C}, 3 \mathrm{~min}\right)$. As shown in Figure 2c (from $\diamond$ to $\Delta$ ), the oocytes swelled from $0.53 \mathrm{~V}$ to $0.59 \mathrm{~V}$, indicating that the intracellular osmotic pressure after treatment was higher than the extracellular osmotic pressure generated by Gly40.

(d) Oocytes $\rightarrow$ EG20 $\left(25^{\circ} \mathrm{C}, 5 \mathrm{~min}\right) \rightarrow$ EG40 $\left(4^{\circ} \mathrm{C}, 30 \mathrm{~s}\right) \rightarrow \operatorname{Gly} 50\left(4^{\circ} \mathrm{C}, 3 \mathrm{~min}\right)$. As shown in Figure $2 \mathrm{~d}$, when the oocytes were flushed with pre-cooled Gly50 followed by a 5 min treatment with EG20 and a 30 s treatment with EG40, no expansion was observed. After immersion in Gly50, the oocytes began to shrink, and within $60 \mathrm{~s}$, the oocytes gradually reached a minimum volume (from $\diamond$ to $\Delta$ in Figure 2d). This result indicated that the intracellular osmotic pressure was not higher than the extracellular osmotic pressure exerted by Gly 50 .

(e) Oocytes $\rightarrow$ EG20 $\left(25^{\circ} \mathrm{C}, 5 \mathrm{~min}\right) \rightarrow$ Gly50

$\left(4^{\circ} \mathrm{C}, 4 \mathrm{~min}\right)$. In this experiment, oocytes were pretreated with EG20 and then flushed with pre-cooled Gly50. Volume changes are shown in Figure 2e. The oocytes shrank quickly in Gly50 after EG20 pretreatment. The oocytes reached a minimum volume ( $\Delta$ part in Figure 2e) within approximately $100 \mathrm{~s}$.

Experiment 2. Development of cryopreserved oocytes after parthenogenetic activation

As shown in Table 1, after vitrification, warming and parthenogenetic activation, surviving bovine oocytes develop to the cleavage stage embryos and blastocysts. After this vitrification protocol, $81.1 \%$ oocytes survived and $63.5 \%$ of them cleaved after parthenogenetic activation. Finally, we observed a $20.0 \%$ blastocyst rate. There was no difference in rates of blastocyst development between the control and toxicity groups (38.6\% vs 36.0\%, $P>0.05)$. However, after oocyte vitrification, the rates of blastocyst development decreased $(P<0.05)$.

\section{Discussion}

There are few reports that analyze vitrification of bovine metaphase oocytes by the straw method. In the present study, we achieved cleavage (63.5\%) and blastocyst development (20.0\%) after parthenogenetic activation of vitrified-warmed bovine oocytes similar to that from oocytes vitrified by the open-pulled straw method $(57.0 \%$ cleavage and $23.0 \%$ blastocyst development, respectively) 


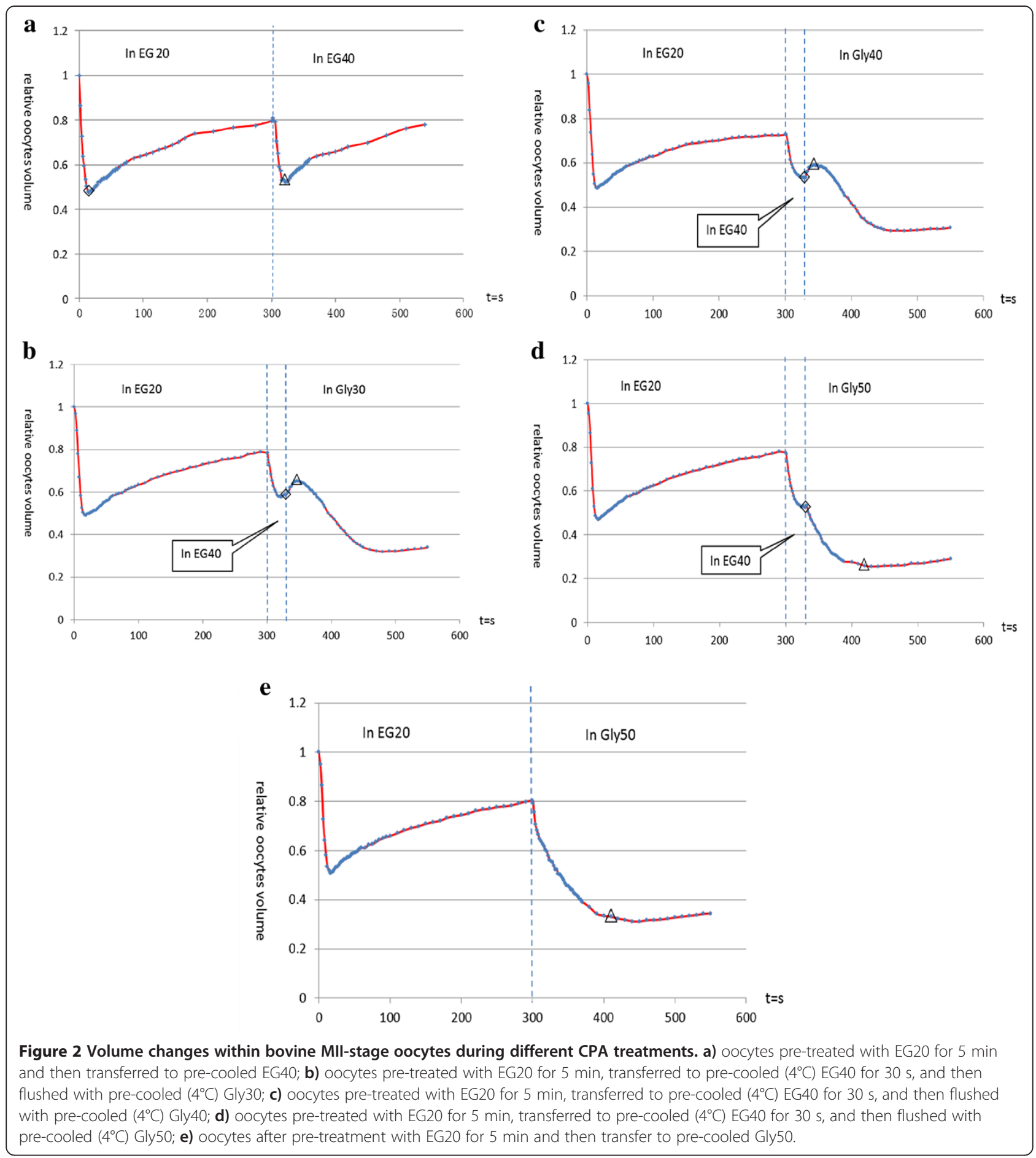

[24]. However, the straw method has an advantage for bovine oocyte vitrification, because oocytes do not directly contact the liquid nitrogen and thus potential bacterial contamination is avoided.

Most two-step vitrification methods are similar, with some differences in exposure time or CPA combination. In fact, exposure times greatly influence the outcome of the vitrification method $[2,7-9,22]$. It has been reported that when bovine blastocysts are exposed to EFS40 from 1 to $3 \mathrm{~min}$, the survival rate drops from $77.0 \%$ to $7.0 \%$ [8]. Campos-Chillon tested a range of pretreatment times (from 1 to $3 \mathrm{~min}$ ) in $3.5 \mathrm{~mol} / \mathrm{L}$ ethylene glycol on bovine morulae and found that a 1-min exposure was ideal [7]. Fujihira found a significant relationship $(P<$ 0.05 ) between the rate of development of morphologically normal oocytes after vitrification and equilibration 
Table 1 Effects of oocyte vitrification on embryo development after parthenogenetic activation

\begin{tabular}{lcccc}
\hline Group & No. oocytes & Survival rate & Cleavage rate & Blastocyst rate \\
\hline Control & 132 & $100 \% \pm 0(132 / 132)^{a}$ & $84.21 \% \pm 2 \%(111 / 132)^{a}$ & $38.62 \% \pm 0.75 \%(51 / 132)^{a}$ \\
Toxicity & 103 & $93.22 \% \pm 1.56 \%(96 / 103)^{b}$ & $76.74 \% \pm 2.27 \%(79 / 96)^{b}$ & $35.93 \% \pm 1.47 \%(37 / 96)^{a}$ \\
Vitrified & 105 & $81.08 \% \pm 2.86 \%(89 / 105)^{c}$ & $63.49 \% \pm 2.1 \%(66 / 105)^{c}$ & $19.96 \% \pm 1.06 \%(21 / 105)^{b}$ \\
\hline
\end{tabular}

Different superscripts $(a, b, c)$ in the same column represent a significant difference $(P<0.05)$. Percentage data are presented as mean \pm SEM.

time in pigs [25]. Others used much longer exposure times $(10-20 \mathrm{~min})$ for oocytes [19] or embryos [21,26] before vitrification. Despite these variations, the ultimate goal of these procedures was to determine proper intracellular concentrations of CPA for successful vitrification of oocytes.

In the present study, bovine oocytes exposed to EG20 for $5 \mathrm{~min}$ and then transferred to EG40 shrank to $0.52 \mathrm{~V}$ before gradually regaining volume. Furthermore, mouse [5] and bovine [15] oocytes exhibited ideal osmotic responses when their volumes were analyzed using the Boyle-van't Hoff relationship. Here, cells stopped shrinking at $0.52 \mathrm{~V}$, which can be inferred as the state of equilibrium between intra- and extracellular osmotic pressures resulting from exposure to hypotonic (swelling) or hypertonic (shrinking) solutions [4]. In subsequent experiments, oocytes were sequentially exposed to EG20 (5 min) and EG40 (30 s) followed by treatment either with Gly30 and Gly40 or Gly50. Volume expansion was observed in Gly30 and Gly40, suggesting that the intracellular osmotic pressure was higher than that produced by Gly40. However, volume expansion did not occur when the oocytes were flushed with Gly50, suggesting that the extracellular osmotic pressure was higher in Gly50 than the intracellular osmotic pressure.

The permeability of CPAs is strongly decreased at low temperatures [15,27]; therefore, during a short exposure of oocytes (30 s) to pre-cooled $\left(4^{\circ} \mathrm{C}\right) \mathrm{EG} 40$ in the second equilibrium step, the intra- and extracellular EG levels changed minimally. As a result, we omitted the EG40 step and modified the second equilibrium step by exposing oocytes to EG20 for $5 \mathrm{~min}$ and to pre-cooled Gly50 for $30 \mathrm{~s}$ before plunging into liquid nitrogen. As shown in Figure 2e, the oocytes shrank to a minimum volume in approximately $100 \mathrm{~s}$, and this shrinking would result in concentration of intracellular EG during this period. It has been reported by Jin [28] that vitrification solutions with higher osmotic pressure could facilitate intracellular vitrification, yielding better results. In Experiment 2, oocytes were vitrified after treatment with pre-cooled $\left(4^{\circ} \mathrm{C}\right)$ Gly50 for $30 \mathrm{~s}$. After warming, $81.1 \%$ of the oocytes survived, and the surviving oocytes developed into cleavage stage embryos (63.5\%) and blastocysts (20.0\%) after parthenogenetic activation. As long as the CPA concentration higher than EFS30 (which corresponds to PB1 medium containing 30\% (v/v ethylene glycol, $21 \%(w / v)$ Ficoll 70 , and $0.35 \mathrm{~mol} / \mathrm{L}$ sucrose) oocytes will not devitrify during warming [29]. The high survival of oocytes here which indicates that the intra- and extracellular CPAs were vitrified during both the freezing and warming procedures.

In this study, we did not compare oocyte survival and development in the absence and presence of Gly50 (after EG20 $(5 \mathrm{~min})>\mathrm{EG} 40(30 \mathrm{~s}))$. We believed that treatment with Gly50 would yield better results, as it has been reported that solutions containing $40 \%$ ethylene glycol remain transparent when plunged into liquid nitrogen but crystallize during warming [29]. Although we can not rule out the possibility that EG leaves the oocytes under high osmotic pressure, the concentration of EG remaining is sufficient to achieve vitrification according to our results in Table 1.

\section{Conclusion}

Results from these experiments provide clear evidence that during the two-step equilibrium before vitrification, if proper pretreatment (EG20 for $5 \mathrm{~min}$ ) was taken, the permeability of CPA into oocytes is unnecessary during the second equilibration step. What is efficient is a vitrification solution (Gly50) with high osmotic pressure only during the second equilibrium period to concentrate the intracellular CPAs adequately to facilitate intracellular vitrification.

\section{Abbreviations}

EG20: 20\% v/v ethylene glycol in mPBS; EG40: 40\% v/v ethylene glycol in mPBS; Gly30: 30\% v/v glycerol in mPBS; Gly40: 40\% v/v glycerol in mPBS; Gly50: 50\% v/v glycerol in mPBS; EFS30: PB1 medium containing 30\% v/v ethylene glycol, $21 \%(\mathrm{~W} / \mathrm{v})$ Ficoll 70 , and $0.35 \mathrm{~mol} / \mathrm{L}$ sucrose;

CPA: Cryoprotective agents; ICCP: Intracellular concentration of cryoprotectant; VS: Vitrification solution; V: Volume; S: Sucrose; Min: Minute; Sec: Second.

\section{Competing interests}

The authors declare that they have no competing interests.

\section{Authors' contributions}

ZYH designed the study, conducted the experiments and analyses and wrote the manuscript. ZSE collaborated in the design of the study and analysis and oversaw the work of laboratory staff. FXW collaborated in the design of the study and the analysis and helped write the manuscript. ZGB collaborated in the design of the study and reviewed the manuscript. JBY selected the assays to measure cross-sectional area and assisted in the interpretation of results. FY helped with the culture of oocytes and early embryos. HYP collaborated in the interpretation of results and writing of the manuscript. All authors read and approved the final manuscript.

\section{Authors' information}

Yanhua Zhou is Ph.D candidate of College of Animal Science and Technology, China Agricultural University, Shien Zhu is professor of College of Animal Science and Technology, China Agricultural University. Xiangwei 
Fu is associate professor of College of Animal Science and Technology, China Agricultural University, Yunpeng Hou is associate professor of State Key Laboratory for Agrobiotechnology, College of Biological Sciences, China Agricultural University, Guangbin Zhou is professor of College of Animal Science and Technology, Sichuan Agricultural University (Chengdu Campus). Baoyu Jia and Yi Fang are Ph.D candidate of College of Animal Science and Technology, China Agricultural University.

\section{Acknowledgments}

This work was supported by the National "863" Project Foundation of China (No. 2011AA100303) and the National Science and Technology Support Projects of China (No. 2011BAD19B01). We thank Nature Publishing Group Language Editing (NPGLE) for proof-reading the manuscript.

\section{Author details}

'National Engineering Laboratory for Animal Breeding, Key Laboratory of Animal genetics, Breeding and Reproduction, Ministry of Agriculture, College of Animal Science and Technology, China Agricultural University, Beijing 100193, P.R. China. ${ }^{2}$ State Key Laboratory for Agrobiotechnology, College of Biological Sciences, China Agricultural University, Beijing 100193, P.R. China. ${ }^{3}$ Institute of Animal Genetics and Breeding, College of Animal Science and Technology, Sichuan Agricultural University (Chengdu Campus), Wenjiang 611130 , P.R. China.

Received: 18 February 2014 Accepted: 8 April 2014

Published: 11 April 2014

\section{References}

1. Rall WF, Fahy GM: Ice-free cryopreservation of mouse embryos at $-196^{\circ} \mathrm{C}$ by vitrification. Nat Commun 1985, 313:573-575.

2. Kuwayama M, Vajta G, Kato O, Leibo SP: Highly efficient vitrification method for cryopreservation of human oocytes. Reprod Biomed Online 2005, 11:300-308

3. Vanderzwalmen P, Ectors F, Grobet $L$, Prapas $Y$, Panagiotidis $Y$, Vanderzwalmen S, Stecher A, Frias P, Liebermann J, Zech NH: Aseptic vitrification of blastocysts from infertile patients, egg donors and after IVM. Reprod Biomed Online 2009, 19:700-707.

4. Vanderzwalmen P, Connan D, Grobet L, Wirleitner B, Remy B, Vanderzwalmen S, Zech N, Ectors FJ: Lower intracellular concentration of cryoprotectants after vitrification than after slow freezing despite exposure to higher concentration of cryoprotectant solutions. Hum Reprod 2013, 28:2101-2110.

5. Liang W, Jun L, Guangbin Z, Yunpeng H, Junjie L, Shien Z: Quantitative investigations on the effects of exposure durations to the combined cryoprotective agents on mouse oocyte vitrification procedures. Biol Reprod 2011, 85:884-894

6. Edashige K, Ohta S, Tanaka M, Kuwano T, Valdez DM, Hara T, Jin B, Takahashi S, Seki S, Koshimoto C: The role of aquaporin 3 in the movement of water and cryoprotectants in mouse morulae. Biol Reprod 2007, 77:365-375.

7. Campos-Chillon LF, Walker DJ, De La Torre-Sanchez JF, Seidel GE Jr: In vitro assessment of a direct transfer vitrification procedure for bovine embryos. Theriogenology 2006, 65:1200-1214.

8. Tachikawa S, Otoi T, Kondo S, Machida T, Kasai M: Successful vitrification of bovine blastocysts, derived by in vitro maturation and fertilization. Mol Reprod Dev 1993, 34:266-271.

9. Vaita G, Holm P, Greve T, Callesen H: Factors affecting survival rates of in vitro produced bovine embryos after vitrification and direct in-straw rehydration. Anim Reprod Sci 1996, 45:191-200.

10. Vajta G, Holm P, Kuwayama M, Booth PJ, Jacobsen H, Greve T, Callesen H: Open pulled straw (OPS) vitrification: a new way to reduce cryoinjuries of bovine ova and embryos. Mol Reprod Dev 1998, 51:53-58.

11. Le Gal F, Massip A: Cryopreservation of cattle oocytes: effects of meiotic stage, cycloheximide treatment, and vitrification procedure. Cryobiology 1999, 38:290-300

12. Dinnyés $A$, Dai $Y$, Jiang $S$, Yang $X$ : High developmental rates of vitrified bovine oocytes following parthenogenetic activation, in vitro fertilization, and somatic cell nuclear transfer. Biol Reprod 2000, 63:513-518.

13. KATO O, NAGAI T: High survival rate of bovine oocytes matured in vitro following vitrification. J Reprod Dev 2004, 50:685-696.
14. Pedro PB, Yokoyama E, Zhu SE, Yoshida N, Valdez DM Jr, Tanaka M, Edashige K, Kasai M: Permeability of mouse oocytes and embryos at various developmental stages to five cryoprotectants. J Reprod Dev 2005, 512:235-246.

15. Wang $X$, Al Naib A, Sun D, Lonergan P: Membrane permeability characteristics of bovine oocytes and development of a step-wise cryoprotectant adding and diluting protocol. Cryobiology 2010, 61:58-65.

16. Whittingham DG: Fertilization in vitro and development to term of unfertilized mouse oocytes previously stored at-196 C. J Reprod Fertil 1977, 49:89-94.

17. Fuku E, Kojima T, Shioya Y, Marcus GJ, Downey BR: In vitro fertilization and development of frozen-thawed bovine oocytes. Cryobiology 1992, 29:485-492.

18. Wani NA, Misra AK, Maurya SN: Maturation rates of vitrified-thawed immature buffalo (Bubalus bubalis) oocytes: effect of different types of cryoprotectants. Anim Reprod Sci 2004, 84:327-335.

19. Yamada C, Caetano HVA, Simões R, Nicacio AC, Feitosa WB, Assumpção MEOD, Visintin JA: Immature bovine oocyte cryopreservation: comparison of different associations with ethylene glycol, glycerol and dimethylsulfoxide. Anim Reprod Sci 2007, 99:384-388.

20. Sharma GT, Dubey PK, Chandra V: Morphological changes, DNA damage and developmental competence of in vitro matured, vitrified-thawed buffalo (Bubalus bubalis) oocytes: a comparative study of two cryoprotectants and two cryodevices. Cryobiology 2010, 60:315-321.

21. Saha S, Otoi T, Takagi M, Boediono A, Sumantri C, Suzuki T: Normal calves obtained after direct transfer of vitrified bovine embryos using ethylene glycol, trehalose, and polyvinylpyrrolidone. Cryobiology 1996, 33:291-299.

22. Zhu SE, Kasai M, Otoge H, Sakurai T, Machida T: Cryopreservation of expanded mouse blastocysts by vitrification in ethylene glycol-based solutions. J Reprod Fertil 1993, 98:139-145.

23. Rosenkrans CF, Zeng GQ, McNamara GT, Schoff PK, First NL: Development of bovine embryos in vitro as affected by energy substrates. Biol Reprod 1993, 49:459-462.

24. Hou Y, Dai Y, Zhu S, Zhu H, Wu T, Gong G, Wang H, Wang L, Liu Y, Li R: Bovine oocytes vitrified by the open pulled straw method and used for somatic cell cloning supported development to term. Theriogenology 2005, 64:1381-1391.

25. Fujihira T, Nagai H, Fukui Y: Relationship between equilibration times and the presence of cumulus cells, and effect of taxol treatment for vitrification of in vitro matured porcine oocytes. Cryobiology 2005, 51:339-343.

26. Van Wagtendonk-de Leeuw AD, Den Daas J, Rall WF: Field trial to compare pregnancy rates of bovine embryo cryopreservation methods: vitrification and one-step dilution versus slow freezing and three-step dilution. Theriogenology 1997, 48:1071-1084.

27. Leibo SP, Mazur P, Jackowski SC: Factors affecting survival of mouse embryos during freezing and thawing. Exp Cell Res 1974, 89:79-88.

28. Jin B, Mochida K, Ogura A, Koshimoto C, Matsukawa K, Kasai M, Edashige K: Equilibrium vitrification of mouse embryos at various developmental stages. Mol Reprod Dev 2012, 79:785-794.

29. Kasai M, Komi JH, Takakamo A, Tsudera H, Sakurai T, Machida T: A simple method for mouse embryo cryopreservation in a low toxicity vitrification solution, without appreciable loss of viability. J Reprod Fertil 1990, 89:91-97.

doi:10.1186/2049-1891-5-19

Cite this article as: Zhou et al:: An efficient method for the sanitary vitrification of bovine oocytes in straws. Journal of Animal Science and Biotechnology 2014 5:19. 